\title{
Correction to: Analysis of One and Two- Story Single Family Home Fire Dynamics and the Impact of Firefighter Horizontal Ventilation
}

*Stephen Kerber, UL LLC, 333 Pfingsten Rd, Northbrook, IL 60062-2096, USA

The article Analysis of One and Two-Story Single Family Home Fire Dynamics and the Impact of Firefighter Horizontal Ventilation, written by Stephen Kerber, was originally published electronically on the publisher's internet portal (currently SpringerLink) on August 29, 2012, without open access.

\section{Correction to: Fire Technology (2013) 49:857-889 https://doi.org/ 10.1007 /s $10694-01$ 2-0294-5}

The article Analysis of One and Two-Story Single Family Home Fire Dynamics and the Impact of Firefighter Horizontal Ventilation, written by Stephen Kerber, was originally published electronically on the publisher's internet portal (currently SpringerLink) on August 29, 2012, without open access.

With the author(s)' decision to opt for Open Choice, the copyright of the article changed on September 20, 2019, to (C) The Author(s) 2019 and the article is forthwith distributed under the terms of the Creative Commons Attribution 4.0 International License (http://creativecommons.org/licenses/by/4.0/), which permits use, duplication, adaptation, distribution and reproduction in any medium or format, as long as you give appropriate credit original author(s) and the source, provide a link to the Creative Commons license and indicate if changes were made.

* Correspondence should be addressed to: Stephen Kerber, E-mail: stephen.kerber@ul.com The original article can be found online at https://doi.org/10.1007/s10694-012-0294-5. 